\title{
Managing and Reducing Uncertainty in an Emerging Influenza Pandemic
}

\section{Citation}

Lipsitch, Marc, Steven Riley, Simon Cauchemez, Azra C. Ghani, and Neil M. Ferguson. 2009.

"Managing and Reducing Uncertainty in an Emerging Influenza Pandemic." N Engl J Med 361 (2) (July 9): 112-115. doi:10.1056/nejmp0904380.

\section{Published Version}

doi:10.1056/nejmp0904380

\section{Permanent link}

http://nrs.harvard.edu/urn-3:HUL.InstRepos:25124695

\section{Terms of Use}

This article was downloaded from Harvard University's DASH repository, and is made available under the terms and conditions applicable to Other Posted Material, as set forth at http:// nrs.harvard.edu/urn-3:HUL.InstRepos:dash.current.terms-of-use\#LAA

\section{Share Your Story}

The Harvard community has made this article openly available.

Please share how this access benefits you. Submit a story.

\section{Accessibility}


Moving ahead now on all these fronts is also important in order to align every stakeholder's interest with value, or reform will once again fail. However, a health care strategy, like any good strategy, involves a sequence of steps over time rather than an attempt to change everything at once. Road maps will be needed for rolling out changes in each area while giving the actors time to adjust.

Some new organizations (or combinations of existing ones) will be needed: a new independent body to oversee outcome measurement and reporting, a single entity to review and set HIT standards, and possibly a third body to establish rules for bundled re- imbursement. Medicare may be able to take the lead in some areas; for example, Medicare could require experience reporting by providers or combine Parts A and $\mathrm{B}$ into one payment.

The big question is whether we can move beyond a reactive and piecemeal approach to a true national health care strategy centered on value. This undertaking is complex, but the only real solution is to align everyone in the system around a common goal: doing what's right for patients.

Dr. Porter reports receiving lecture fees from the American Surgical Association, the American Medical Group Association, the World Health Care Congress, Hoag Hospital, and the Children's Hospital of Philadelphia, receiving director's fees from Thermo Fisher Scientific, and having an equity interest in Thermo Fisher Scientific, Genzyme, Zoll Medical, Merck, and Pfizer. No other potential conflict of interest relevant to this article was reported.

This article (10.1056/NEJMp0904131) was published on June 3, 2009, at NEJM.org.

From Harvard Business School, Boston.

1. Porter ME, Teisberg EO. Redefining health care: creating value-based competition on results. Boston: Harvard Business School Press, 2006.

2. TeperiJ, Porter ME, Vuorenkoski L, BaronJF. The Finnish health care system: a value-based perspective. Helsinki: Sitra, March 2009.

3. Porter ME, Yasin ZM, Baron JF. Global health partner: obesity care. Boston: Harvard Business School Publishing, 2009.

4. Porter ME, Guth C, Dannemiller E. The West German Headache Center: integrated migraine care. Boston: Harvard Business School Publishing, 2007.

5. Porter ME. Value-based health care delivery. Ann Surg 2008;248:503-9.

Copyright (C) 2009 Massachusetts Medical Society.

\section{Managing and Reducing Uncertainty in an Emerging Influenza Pandemic}

Marc Lipsitch, D.Phil., Steven Riley, D.Phil., Simon Cauchemez, Ph.D., Azra C. Ghani, Ph.D., and Neil M. Ferguson, D.Phil.

The early phases of an epidemic present decision makers with predictable challenges ${ }^{1}$ that have been evident as the current novel influenza A (H1N1) virus has spread. The scale of the problem is uncertain when a disease first appears but may increase rapidly. Early action is required, but decisions about action must be made when the threat is only modest - and consequently, they involve a trade-off between the comparatively small, but nearly certain, harm that an intervention may cause (such as rare adverse events from large-scale vaccination or economic and social costs from school dismissals) and the uncertain probability of much greater harm from a widespread outbreak. This combination of urgency, uncertainty, and the costs of interventions makes the effort to control infectious diseases especially difficult.

Plans for addressing influenza pandemics define a graded series of responses to emerging pandemic viruses, ranging from very limited interventions to stringent measures such as closing schools and other public venues, encouraging people to work at home, and using antiviral drugs for treatment and prophylaxis. Such grading of responses is based on the pandemic's severity; for example, the United States' Pandemic Severity Index is calibrated to the case fatality ratio ( $w w w$. pandemicflu.gov/plan/community/ community_mitigation.pdf). Mild responses are prescribed for a strain resembling seasonal influenza, which kills perhaps $0.1 \%$ of those infected, with higher rates in the very young and elderly, whereas stringent measures are envisioned for a very severe pandemic with a case fatality ratio of $2 \%$ or more and deaths concentrated in the middle age groups.

This approach makes sense in theory, but in practice, decisions have had to be made before definitive information was available on the severity, transmissibility, or natural history of the new H1N1 virus. The United States, for example, passed the 1000-case mark on May 4, and the second death was reported on May 5. Crudely speaking, the case fatality ratio thus appeared to be $0.2 \%$, near the upper end of the range for seasonal influenza, and superficially, this statistically uncertain estimate seems remarkably accurate given the data available on May 27, by which point there were 11 deaths and 7927 confirmed cases (a case fatality ratio of $0.14 \%)$.

However, two principal sourc- 
es of uncertainty critically affect severity estimates. The proportion of severe cases is overestimated in settings where many mild cases are not reported or tested, a situation that is becoming more common as public health officials become unable to test a large fraction of suspected cases. In contrast, severity estimates are biased downward when they are calculated as simple ratios of numbers of deaths to numbers of cases, because there is a delay between the onset of illness and death. During the 1918 influenza pandemic, the mean time from symptom onset to death was 8 to 9 days, ${ }^{2}$ whereas the number of cases was doubling about every 3 days. With a similar delay, today's deaths would reflect the state of the epidemic three doublings ago, when there were about one eighth the number of cases there are now. If modern therapies have extended the time between onset and death, the censoring bias will be even more pronounced. Such uncertainty has made it impossible to assess severity confidently.

Moreover, several other factors suggest that it is premature to dismiss concerns about severity. First, this virus tends to infect relatively young, healthy people, and it caused a high hospitalization rate of $2 \%$ in the United States even before testing shifted to emphasize severe cases. ${ }^{3}$ Second, the much higher proportion of people likely to be infected in a pandemic (because of limited immunity to the new strain) will mean substantially higher levels of severe outcomes than usual. A virus that is fatal in "only" $0.15 \%$ of cases but infects twice the typical number of people would cause about three times as many deaths as typical influenza, or more than 100,000 deaths in the United States. Moreover, this "mild" illness will almost certainly take a more severe toll in less wealthy countries, as infectious diseases routinely do. The Northern Hemisphere may see a decline in transmission over the summer, but the 1918 pandemic demonstrated that sustained spring and summer transmission is possible for a novel influenza strain, and the Southern Hemisphere is entering its influenza season now. The Southern Hemisphere, at least, and possibly the entire world, is likely to see a substantial epidemic of this virus in the next few months, with attack rates exceeding those in a typical influenza season, before significant quantities of vaccine become available.

Paradoxically, uncertainty about this infection's characteristics is likely to increase further as the Northern Hemisphere's summer progresses. The low specificity of clinical signs and symptoms, combined with changes in reporting practices, will make it difficult to interpret apparent incidence trends at the national level. Without reliable incidence measures, it is impossible to track the epidemic's growth rate, which makes estimates of transmissibility highly uncertain and subject to biases because of changes in the probability of detection. School absences, a crude measure of epidemic spread, will become less informative once most schools are closed for the summer. Without good incidence estimates, estimates of severity will continue to suffer from an uncertain denominator. The effectiveness of control measures will be difficult to assess without accurate measures of local incidence. When a vaccine becomes available, appropriate targeting of limited supplies will require knowledge of levels of preexisting immunity, age-specific severity estimates, and other quantities that depend on reliable measures of the incidence of mild and severe disease.

If we could be sure that the infection would remain mild in most cases, these uncertainties would be similar to those we tolerate in a normal influenza season, although the numbers affected would probably be larger. But historically, pandemic viruses have evolved between seasons, ${ }^{4,5}$ and the current strain may become more severe or transmissible in the coming months. Thus, decision makers in both hemispheres could again face uncertainty about the characteristics of a possibly evolving virus in the coming half-year.

There is a brief window of opportunity to take measures to reduce the uncertainty. Serologic studies in the tropics during the Northern Hemisphere summer and at higher latitudes in both hemispheres will permit estimation of the extent of spread of mild infection. If transmission wanes in the north, a late-summer serologic survey will provide baseline information about population immunity that will aid in both vaccine targeting and interpretation of patterns of illness in the fall.

Serologic surveys represent snapshots of the population rather than real-time measures of incidence. Additional surveillance is needed to quantify the incidence of mild and severe infection in nearly real time. Surveillance for nonspecific indicators, such as visits to health care providers for influenza-like illness or hospitalization for pneumonia, can provide an indication of the total disease burden but cannot determine causation. Such surveillance should be combined with routine 
testing of a systematic sample of patients to estimate the total burden of H1N1-attributable disease. In combination with serologic surveys, such surveillance would allow public health officials to estimate the proportions of infections leading to mild and severe illness and to determine how they vary with age and other risk factors. Detailed outbreak investigations in households and schools would elucidate transmission dynamics and inform recommendations on containment measures. Although cases detected by routine surveillance are subject to case-ascertainment bias, secondary cases in a household or a school outbreak constitute an unbiased sample that can be used to estimate illness severity. Household-transmission studies also provide information on age-specific susceptibility profiles while controlling for levels of exposure.

Augmenting traditional surveillance systems to measure the new virus's spread should be a high priority. Since the measures outlined above are expensive and require substantial infrastructure, they are practical for only a limited number of sentinel sites. To extend the range of surveillance, nontraditional approaches may be important. Web-based incidence surveys may be practical if there are adequate incentives to respond and adequate privacy assurances. Daily school absences should be tracked according to grade and school and made available for real-time analysis. Use of mobile phones for repeated surveys of large population samples may be another method for real-time surveillance in areas where more traditional approaches are impossible or too expensive. Though such approaches cannot discern the cause of illness, they compensate with greater coverage and speed of data availability. The value of these approaches will be greatest if they are also conducted in areas where more traditional surveillance is also under way, so that their relationship to validated measures of virologically confirmed incidence can be calibrated.

International cooperation will be crucial, not only to enhance capacity for surveillance in the tropics and the Southern Hemisphere but also to monitor changes in antigenicity, severity, transmissibility, and antiviral resistance that may be reflected in a fall wave in the Northern Hemisphere. Many approaches suggested here to improve awareness of the epidemic during the Northern Hemisphere's fall can be applied more immediately in the tropics and the Southern Hemisphere during the upcoming influenza seasons there.

Surveillance systems and our understanding of the dynamics of infectious-disease transmission have improved substantially since the 1968 influenza pandemic. These improvements can be used to support policymakers in managing the current pandemic. If new data-collection systems capable of reducing key uncertainties are to be implemented in time for the autumn, international and intersector cooperation leveraging the expertise of the university and private sectors must be combined with rapid enhancement of traditional, government-sponsored surveillance.

Public communication of risk and uncertainty will be critical. It has been suggested that the existing criteria for moving to World Health Organization pandemic phase 6 (sustained transmission in multiple geographic regions) should be modified to incorporate a judgment that the world's population is at increased risk. We would argue against con- flating assessments of transmissibility and severity in this subjective way, which risks adding to the confusion faced by decision makers and the public. Rather, the global extent of a pandemic should be described objectively and should be just one factor in decisions about how to respond.

As we adjust our mitigation policies, there will be a continuing need to make decisions without definitive estimates of severity. For example, the decision to move from production of vaccine for seasonal influenza to that for pandemic influenza will need to be made in the next month or two. Similarly, the United States will need to decide soon whether to use adjuvanted vaccines to protect more people with a given amount of antigen, although such vaccines are not currently licensed in the United States. As always, however, the main losers from delays in such decisions are likely to be developing countries, which will have less access to vaccine while probably suffering the greatest clinical impact from this new pandemic virus.

Dr. Lipsitch reports receiving consulting fees from the Avian/Pandemic Flu Registry (Outcome Sciences); Dr. Cauchemez, consulting fees from Sanofi Pasteur MSD; and Dr. Ferguson, consulting fees from Serco; advisory fees from Novartis, Roche, and GlaxoSmithKline; and lecture fees from Roche. No other potential conflict of interest relevant to this article was reported.

This article (10.1056/NEJMp0904380) was published on May 27, 2009, and was last updated on May 28, 2009, at NEJM.org.

From the Harvard School of Public Health, Boston (M.L.); the Department of Community Medicine, Li Ka Shing Faculty of Medicine, and the School of Public Health, University of Hong Kong - both in Hong Kong (S.R.); and the Medical Research Council Centre for Outbreak Analysis and Modeling, Department of Infectious Disease Epidemiology, Imperial College London, London (S.C., A.C.G., N.M.F.).

1. Neustadt RE, Fineberg $\mathrm{H}$. The epidemic that never was: policy-making and the swine flu affair. New York: Vintage Books, 1983. 
2. Brundage JF, Shanks GD. Deaths from bacterial pneumonia during 1918-19 influenza pandemic. Emerg Infect Dis 2008;14:1193-9. 3. Update: novel influenza $A(\mathrm{HlNl})$ virus infections - worldwide, May 6, 2009. MMWR Morb Mortal Wkly Rep 2009;58:453-8.
4. Andreasen V, Viboud C, Simonsen L. Epidemiologic characterization of the 1918 influenza pandemic summer wave in Copenhagen: implications for pandemic control strategies. J Infect Dis 2008;197:270-8.

5. Viboud C, Grais RF, Lafont BA, Miller MA,
Simonsen L. Multinational impact of the 1968 Hong Kong influenza pandemic: evidence for a smoldering pandemic. J Infect Dis 2005;192:233-48.

Copyright (C) 2009 Massachusetts Medical Society.

\section{Geographic Dependence, Surveillance, and Origins of the 2009 Influenza A (H1N1) Virus}

Vladimir Trifonov, Ph.D., Hossein Khiabanian, Ph.D., and Raul Rabadan, Ph.D.

Tn April 2009, a new strain of Lhuman H1N1 influenza A vi-

rus was identified in Mexico. According to the World Health

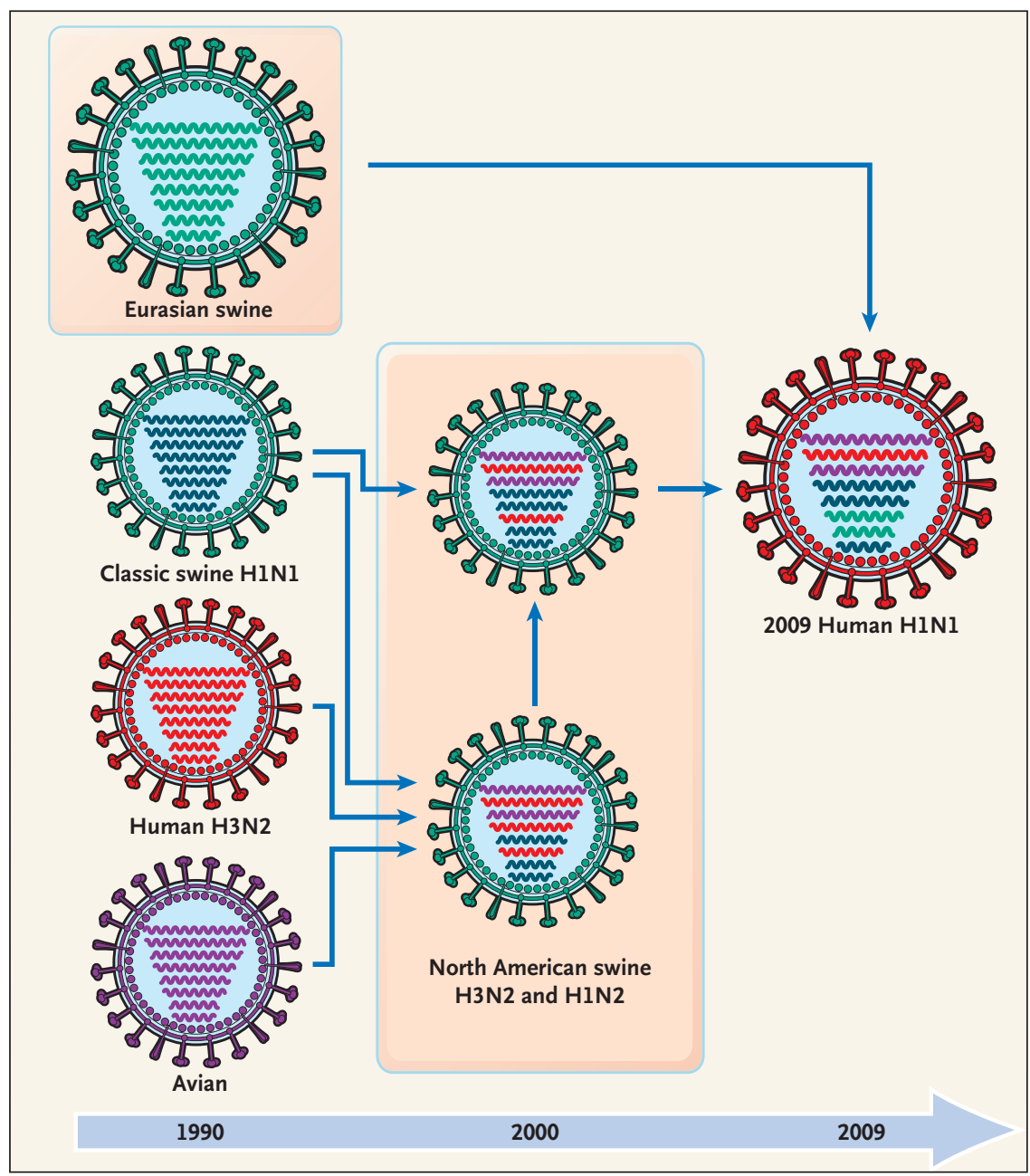

Figure 1. History of Reassortment Events in the Evolution of the 2009 Influenza A (HIN1) Virus. The eight segments shown within each virus code for the following proteins of the influenza $A$ virus (top to bottom): polymerase PB2, polymerase PB1, polymerase PA, hemagglutinin, nuclear protein, neuraminidase, matrix proteins, and nonstructural proteins. The segments of the human 2009 influenza A ( $\mathrm{HINl}$ ) virus have coexisted in swine influenza A virus strains for more than 10 years. The ancestors of neuraminidase have not been observed for almost 20 years. The mixing vessel for the current reassortment is likely to be a swine host but remains unknown.
Organization (www.who.int/csr/ don/2009_05_25), as of May 25, 2009, the virus had spread to 43 countries, with 12,515 reported cases and 91 associated deaths, and it has been assessed as having pandemic potential. ${ }^{1}$

Genomic analysis of the 2009 influenza A (H1N1) virus in humans indicates that it is closely related to common reassortant swine influenza A viruses isolated in North America, Europe, and Asia (Fig. 1). ${ }^{2-4}$ The segments coding for the polymerase complex, hemagglutinin, nuclear protein, and nonstructural proteins show high similarity with the swine H1N2 influenza A viruses isolated in North America in the late 1990s (Table 1). H1N2 and other subtypes are descendants of the triple-reassortant swine H3N2 viruses isolated in North America. They have spread in swine hosts around the globe and have been found to infect humans. ${ }^{5}$ The segments coding for the neuraminidase and the matrix proteins of the new human H1N1 virus are, however, distantly related to swine viruses isolated in Europe in the early 1990s (Table 2). In particular, the closest isolated relatives of the neuraminidase segment have 94.4\% similarity at the nucleotide level with European swine influenza A virus strains from 1992.

In the past few years, there 